\title{
EL BOOKTRAILER: UNA PROPUESTA INNOVADORA PARA EVALUAR LA COMPETENCIA LINGÜÍSTICA EN LA EDUCACIÓN PRIMARIA
}

The booktrailer: An innovative proposal to evaluate linguistic competence in Primary

\section{Education}

O booktrailer: Uma proposta inovadora para avaliar a competência linguística na Educação Primária

\author{
Ma Amparo Torres Bellvís (1)
}

$M^{a}$ Amparo Calatayud Salom (2)

(1) Doctoranda del Programa de Doctorado en Educación. Universidad de Valencia, España. Teléfono +34 607163613. Correo electrónico: matobell@alumni.uv.es

(2) Profesora Titular de Universidad. Dpto. de Didáctica y Organización Escolar. Universidad de Valencia, España. Teléfono: +34 963864427. Correo electrónico: amparo.calatayud@uv.es

\section{Resumen}

En el contexto educativo y desde el área de Lengua y Literatura Castellana, se plantea la implementación del booktrailer como propuesta innovadora para el desarrollo del fomento de la lectura, la adquisición de hábitos lectores y para la evaluación de la competencia lingüística en la Educación Primaria. De este modo y mediante una rúbrica, se presenta una experiencia realizada con estudiantes de los dos últimos cursos de Educación Primaria, constatando que es posible evaluar desde la vertiente formativa la competencia lingüística de otra manera más lúdica y significativa, teniendo como punto de partida los elementos y características de los epítextos digitales puramente consumistas y los aspectos a evaluar para el desarrollo de la competencia lectora de los informes PISA.

Palabras clave: Booktrailer, rúbricas evaluativas, competencia lingüistica, innovación educativa, educación primaria

\begin{abstract}
In the educational context, from the area of Spanish Language and Literature, the implementation of the booktrailer is proposed as an innovative proposal for the development of the promotion of reading, the acquisition of reading habits and for the evaluation of the linguistic competence in Primary Education. In this way and through a
\end{abstract}

El booktrailer: una propuesta innovadora para evaluar la competencia lingüística en la Educación Primaria 
rubric, an experience is presented with students of the last two years of Primary Education, stating that it is possible to evaluate, from the training aspect, the linguistic competence in another playful and meaningful way, having as a starting point the elements and characteristics of the purely consumer digital texts and the aspects to be evaluated for the development of the reading competence of the PISA reports.

Keywords: Booktrailer, evaluative rubrics, linguistic competence, educational innovation, primary education

\section{Resumo}

No contexto educativo, a partir da área de Língua e Literatura Castelhana, propõe-se a implementação do booktrailer como proposta inovadora para o desenvolvimento e aquisição de hábitos de leitura e para a avaliação da competência linguística no Ensino Primário. Desta forma e através de uma rubrica, é apresentada uma experiência com alunos dos dois primeiros anos do Ensino Básico, mostrando que é possível avaliar a competência linguística de uma forma mais lúdica e significativa, a partir da vertente formativa e tendo como ponto de partida, os elementos e características dos epítextos puramente digitais dos consumidores e os aspetos a avaliar para o desenvolvimento da competência de leitura dos relatórios PISA.

Palavras-chave: Booktrailer, rubricas avaliativas, competência linguística, inovação educativa, educação primária

\section{Introducción}

En el siglo XXI, indiscutiblemente caracterizado por la irrupción de la tecnología y sus avances en todos los aspectos de nuestras rutinas diarias y, donde las redes sociales juegan un papel decisivo dentro del nuestra sociedad, el fomento de la lectura se ha abierto camino a través del booktrailer.

De esta forma, el booktrailer, epitexto digital, que hasta ahora era empleado por editoriales para condicionar el consumo e incidir en la difusión de un libro (TaberneroSala, 2016) en estos momentos, está incidiendo en determinar una propuesta de innovación educativa en algunos centros de Educación Primaria de la Comunidad Valenciana. Dicho instrumento se concibe como una herramienta para el fomento, la motivación e interés por la lectura, así como también, para la evaluación de la 
competencia lingüística desde la vertiente formativa. (Rovira-Collado \& Llorens García, 2017).

Por consiguiente, esta comunicación, tanto desde su vertiente teórica como practica llevada a cabo en el CEIP Santa Teresa de Villena (Alicante) con un total de 27 estudiantes de quinto y sexto de primaria, ayudará a vislumbrarla como una herramienta útil para la evaluación del proceso lector $\mathrm{y}$, especialmente, para favorecer la retroalimentación del estudiante para la mejora de sus capacidades, "indicando algo más que la diferencia entre el progreso actual y el progreso deseado" (Wiliam, 2011, p. 11).

\section{Contextualización}

La implementación de esta propuesta innovadora basada en la utilización del booktrailer para la evaluación de la competencia lingüística a través de una rúbrica, ha sido desarrollada en la asignatura de Lengua y Literatura Castellana del Centro Educación de Acción Singular (CAES) Santa Teresa de Villena, tomando como muestra los estudiantes de quinto y sexto de Educación Primaria, en un total de 27 estudiantes, habiendo realizado esta selección por el grado de madurez y la capacidad de análisis y valoración crítica que presentan los niños y las niñas de estas edades.

Así pues, esta propuesta innovadora y su evaluación se ejecutó durante el desarrollo de la unidad didáctica "Los cuentos de ahora y de siempre", ubicada en el segundo trimestre escolar del curso académico 2018-19.

\section{Diseño y desarrollo}

Para el diseño de esta propuesta innovadora que presenta como objetivo evaluar la competencia lingüística a través de una rúbrica que contenga las múltiples posibilidades que ofrece el booktrailer, al tiempo que se desarrolla el hábito lector a través de la puesta en práctica de propuestas innovadores de carácter digital que respondan a las necesidades del alumnado, se han tenido en cuenta:

- Los elementos y características de los epitextos digitales que recogen Rovira-Collado, Llorens García, Fernández Tarí \& Mendioal Oñate (2016) en su artículo "Nuevas perspectivas en la didáctica de la literatura infantil y juvenil".

- Los aspectos a evaluar para el desarrollo de la competencia lectora de los informes PISA (2010, p. 7).

El booktrailer: una propuesta innovadora para evaluar la competencia lingüística en la Educación 
Por consiguiente, y tomando como referencia los elementos destacados, se ha elaborado una rúbrica para evaluar la competencia lingüística en el área de lengua y literatura, tal y como se observa en la Figura 1.

\begin{tabular}{|c|c|c|c|c|}
\hline INDICADORES & EXCELENTE (4) & BUENO [3] & REGULAR [2] & INADECUADO [1] \\
\hline $\begin{array}{l}\text { Selección del } \\
\text { contenido (105) }\end{array}$ & $\begin{array}{l}\text { Selección de un relato } \\
\text { corto con argumento } \\
\text { interesante y } \\
\text { adecuado a la edad }\end{array}$ & $\begin{array}{l}\text { Selección de un relat } \\
\text { corto con argumento } \\
\text { interesante pero } \\
\text { infantil para la edad }\end{array}$ & $\begin{array}{l}\text { Selección de un } \\
\text { relato corto con } \\
\text { argumento sin } \\
\text { interés pero } \\
\text { adecuado para la } \\
\text { edad }\end{array}$ & $\begin{array}{l}\text { Selección de un } \\
\text { relato corto con } \\
\text { argumento sin } \\
\text { interés e infantil } \\
\text { para la edad }\end{array}$ \\
\hline $\begin{array}{l}\text { Obtención de } \\
\text { información } \\
\text { (155) }\end{array}$ & $\begin{array}{l}\text { Búsqueda de } \\
\text { información sobre el } \\
\text { autory el relato en } \\
\text { diferentes entornos } \\
\text { (digital, biblioteca...) }\end{array}$ & $\begin{array}{c}\text { Búsqueda de } \\
\text { información sobre el } \\
\text { autor y el relab en un } \\
\text { único entorno }\end{array}$ & $\begin{array}{l}\text { Búsqueda de } \\
\text { información sobre el } \\
\text { relato en diferentes } \\
\text { entornos (digital, } \\
\text { biblioteca...) }\end{array}$ & $\begin{array}{c}\text { Búsqueda de } \\
\text { información sobre el } \\
\text { autor en diferentes } \\
\text { entornos (digital, } \\
\text { biblioteca) }\end{array}$ \\
\hline $\begin{array}{l}\text { Reflexión del } \\
\text { formato (155) }\end{array}$ & $\begin{array}{l}\text { Elaboración de un } \\
\text { guión con el orden de } \\
\text { los puntos a tratar, } \\
\text { identificando el } \\
\text { momento de las } \\
\text { imágenes resumen y } \\
\text { las pausas musicales }\end{array}$ & $\begin{array}{l}\text { Elaboración de un } \\
\text { guión con el orden de } \\
\text { los puntos a tratar, } \\
\text { identificando el } \\
\text { momento de las } \\
\text { imágenes }\end{array}$ & $\begin{array}{c}\text { Elaboración de un } \\
\text { guión con el orden } \\
\text { de los puntos a } \\
\text { tratar. }\end{array}$ & $\begin{array}{l}\text { Falta de un guión } \\
\text { con el orden de los } \\
\text { puntos a tratar. }\end{array}$ \\
\hline $\begin{array}{l}\text { Interpretación } \\
\text { del contenido } \\
\text { (15\%) }\end{array}$ & $\begin{array}{l}\text { Es posible realizar un } \\
\text { resumen completo } \\
\text { del booktrailer, } \\
\text { después de } \\
\text { visualizarlo }\end{array}$ & $\begin{array}{l}\text { Es posible realizar un } \\
\text { resumen del } \\
\text { booktrailer, después } \\
\text { de visualizarlo }\end{array}$ & $\begin{array}{l}\text { Podria escribir una } \\
\text { líneas (ideas, } \\
\text { aspectos concretos) } \\
\text { sin llegar a realizar } \\
\text { un resumen, } \\
\text { después de visualer } \\
\text { el booktrailer }\end{array}$ & $\begin{array}{l}\text { Es muy dificil escribir } \\
\text { unas lineas sobre el } \\
\text { contenido del } \\
\text { booktrailer después } \\
\text { de visualizarlo }\end{array}$ \\
\hline $\begin{array}{l}\text { Reflexión del } \\
\text { contenido (15\%) }\end{array}$ & $\begin{array}{l}\text { El booktrailer recoge } \\
\text { todos los aspectos } \\
\text { recogidos en el guión } \\
\text { de forma clara y } \\
\text { ordenada }\end{array}$ & $\begin{array}{l}\text { El booktrailer recoge } \\
\text { todos los aspectos } \\
\text { recogidos en el guión } \\
\text { de manera clara pero } \\
\text { desordenada }\end{array}$ & $\begin{array}{c}\text { El booktrailer recog } \\
\text { todos los aspectos } \\
\text { recogidos en el } \\
\text { guión pero de } \\
\text { manera } \\
\text { desordenada y poco } \\
\text { clara }\end{array}$ & $\begin{array}{l}\text { El booktrailer no } \\
\text { recoge todos los } \\
\text { aspectos recogidos } \\
\text { en el guión }\end{array}$ \\
\hline $\begin{array}{ll}\text { Evaluación } & \text { del } \\
\text { texto } y & \text { su } \\
\text { comprensión } & \\
\text { global(155) } & \end{array}$ & $\begin{array}{l}\text { El tráiler proporciona } \\
\text { información extra del } \\
\text { relato, es de corta } \\
\text { duración y de gran } \\
\text { intensidad, } \\
\text { enganchando al } \\
\text { público }\end{array}$ & $\begin{array}{l}\text { El tráiler proporciona } \\
\text { información extra del } \\
\text { relato y es de gran } \\
\text { intensidad, } \\
\text { enganchando al } \\
\text { público }\end{array}$ & $\begin{array}{c}\text { El tráiler } \\
\text { proporciona } \\
\text { información extra } \\
\text { del relato, } \\
\text { enganchando al } \\
\text { público }\end{array}$ & $\begin{array}{c}\text { El tráiler no } \\
\text { proporciona } \\
\text { información extra, } \\
\text { solo cuenta aspectos } \\
\text { concretos del relato } \\
\text { y no engancha al } \\
\text { público }\end{array}$ \\
\hline $\begin{array}{l}\text { Evaluación del } \\
\text { formato (155) }\end{array}$ & $\begin{array}{c}\text { El booktrailer } \\
\text { contiene: } \\
\text { presentación del } \\
\text { relato, información del } \\
\text { autor y editorial; } \\
\text { selección de aspectos } \\
\text { más importantes; } \\
\text { imágenes y dónde } \\
\text { poderlo encontrar }\end{array}$ & $\begin{array}{l}\text { El booktrailer } \\
\text { contiene: } \\
\text { presentación del } \\
\text { relato; selección de } \\
\text { aspectos más } \\
\text { importantes; } \\
\text { imágenes y dónde } \\
\text { poderlo encontrar }\end{array}$ & $\begin{array}{l}\text { El booktrailer } \\
\text { contiene: } \\
\text { presentación del } \\
\text { relato; selección de } \\
\text { aspectos más } \\
\text { importantes e } \\
\text { imágenes }\end{array}$ & $\begin{array}{l}\text { El booktrailer } \\
\text { contiene: } \\
\text { presentación del } \\
\text { relato y selección de } \\
\text { aspectos más } \\
\text { importantes }\end{array}$ \\
\hline
\end{tabular}

Figura 1. Rúbrica para la evaluación de la competencia lingüística a través del booktrailer

Así pues, para el desarrollo de esta propuesta basada en la implementación del booktrailer y la evaluación, a través de ésta, de la competencia lingüística mediante una rúbrica, se ha desarrollado el plan de implementación presente en la Tabla 1 desarrollado a lo largo de la segunda quincena del mes de febrero.

El booktrailer: una propuesta innovadora para evaluar la competencia lingüística en la Educación 
Tabla 1.

Programa para la implementación del booktrailer y la evaluación de la competencia lingüística a través de una rúbrica

\begin{tabular}{|c|c|c|}
\hline & TAREA & DURACIÓN \\
\hline SESIÓN 1 & $\begin{array}{l}\text { Presentación de la propuesta innovadora a través de } \\
\text { ejemplificaciones y establecimiento de grupos de trabajo }\end{array}$ & $45^{\prime}$ \\
\hline SESIÓN 2 & Selección del relato corto & $45^{\prime}$ \\
\hline SESIÓN 3 & $\begin{array}{l}\text { Búsqueda de información sobre el autor y sobre el argumento del } \\
\text { relato }\end{array}$ & $45^{\prime}$ \\
\hline SESIÓN 4 & Elaboración del guión para la realización del booktrailer & $45^{\prime}$ \\
\hline SESIÓN 5 & Grabación del argumento del booktrailer & $45^{\prime}$ \\
\hline SESIÓN 6 & Edición del booktrailer & $45^{\prime}$ \\
\hline SESIÓN 7 y 8 & $\begin{array}{l}\text { Visualización de las propuestas, valoración y reflexión sobre las } \\
\text { mismas }\end{array}$ & 90 ' \\
\hline
\end{tabular}

\section{Evaluación y conclusiones}

Por consiguiente, del análisis de implementación del booktrailer como propuesta innovadora en el ámbito de la Educación Primaria para la evaluación de la competencia lingüística se desprenden las siguientes conclusiones:

- Los epitextos digitales favorecen la utilización de herramientas digitales, imprescindible para el afianzamiento de la Escuela 2.0

- Los booktrailers no sólo pueden ser empleados para la formación de lectores competenciales, sino que también pueden ser tenidos en cuenta para la evaluación de la competencia lectora y, por tanto, de la literaria.

- Los booktrailers posibilitan un recurso motivador para la puesta en práctica de la evaluación formativa, así como también, favorecen procesos de autoevaluación y de feedback tal y como nos ha demostrado la experiencia realizada.

- El uso de rúbricas evaluativas durante el desarrollo de propuestas innovadoras y para su valoración final, permite al alumnado ser más consciente de aquellos aspectos que ha de afianzar para obtener una evaluación satisfactoria.

- La utilización de rúbricas en el aula y, en este caso, para la puesta en práctica de esta propuesta innovadora, permite no sólo evaluar el grado de competencia lingüístico adquirido por el alumnado, sino que también posibilita valorar la calidad del booktrailer. 


\section{Referencias}

INECSE (2010). Programa PISA, Pruebas de comprensión lectora. Recuperado de http://www.mecd.gob.es/dctm/ievaluacion/internacional/pisa2000cuadlectura3.p df?documentId=0901e72b80110627

Book Trailers (2012). ¿Qué es un book-tráiler? Recuperado de https://www.booktrailersweb.es/qu\%C3\%A9-es-un-book-trailer/

Rovira-Collado, J., Llorens García, R., Fernández Tarí, S., \& Mendiola Oñate, P. (2016). Nuevas perspectivas en la didáctica de la literatura infantil y juvenil: booktrailer y booktuber. Alicante: Universidad de Alicante, Vicerrectorado de Calidad e Innovación Educativa, Instituto de Ciencias de la Educación (ICE), $1755-1771$

Rovira-Collado, J., \& Llorens García, R. (2017). Epitextos digitales como estrategia LIJ 2.0 para la formación integral en Didáctica de la Lengua y la Literatura. En R. Roig-Vila (Ed.), Investigación en docencia universitaria. Diseñado el futuro a partir de la innovación educativa (pp. 4-14). Barcelona: Octaedro.

Tabernero-Sala, R. (2016). Los epitextos virtuales en la difusión del libro infantil: Hacia una poética del book-trailer. Un modelo de análisis: Revista de Estudios sobre Lectura OCNOS, 15(2), 21-26

William, D. (2011). Embedded formative assessment. Bloomington, IN. 47404: Solution Tree. 